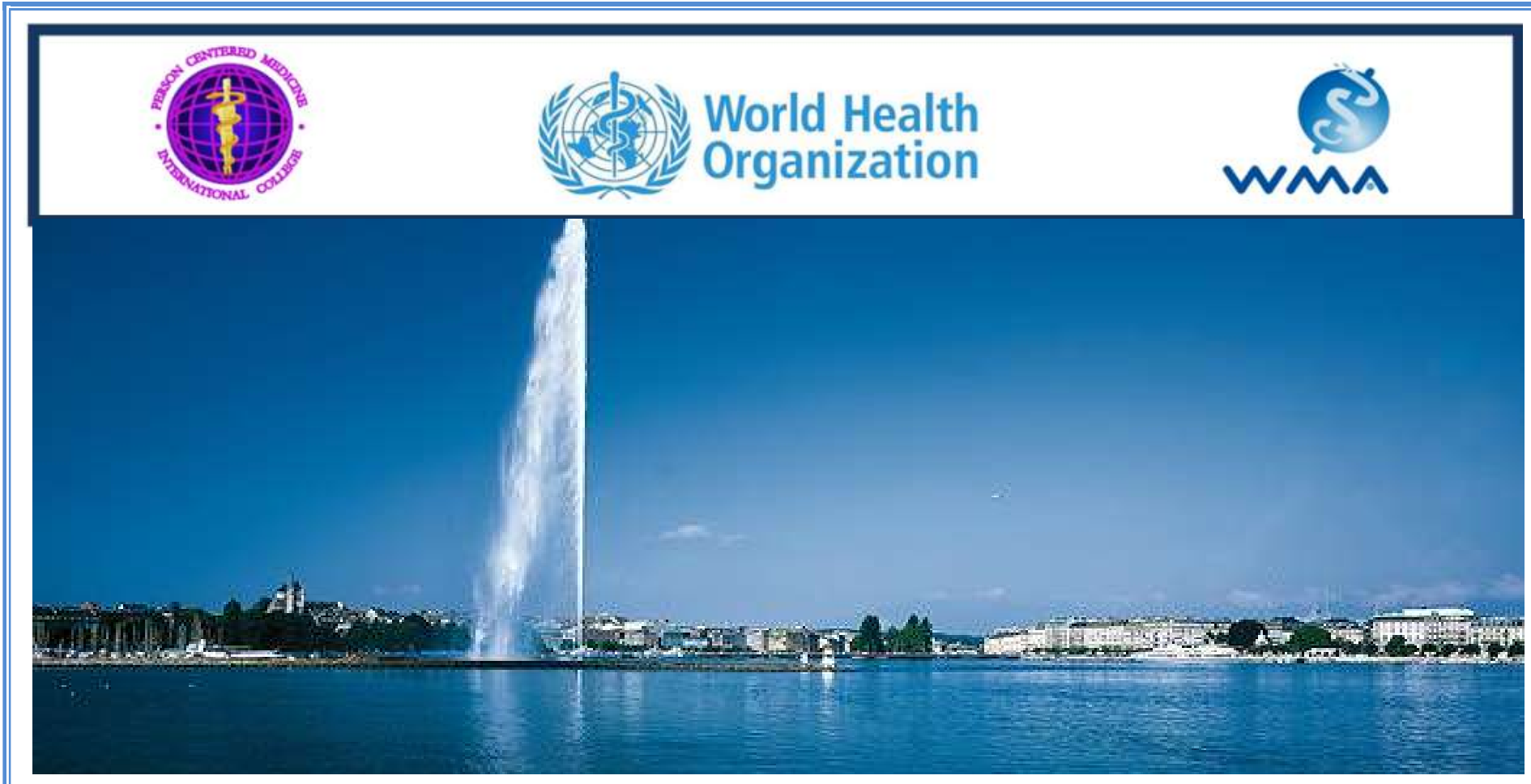

9th GENEVA CONFERENCE ON PERSON-CENTERED MEDICINE

Person-Centered Integrated Care through the Life Course

April 10 - 13, 2016

Geneva University Hospital and World Health Organization

CONFERENCE ANNOUNCEMENT

Organized by the International College of Person-centered Medicine in collaboration with the World Health Organization, the World Medical Association and other top global medical and health bodies.

Expected participants will be clinicians and scholars in medicine and related health disciplines as well as other health stakeholders. The registration fee is 450 Euros for persons residing in World Bank Group A (High Income Countries) and 300 Euros for persons from other countries. Documented full time students and members of patient and family associations will pay discounted half-rate fees.

ICPCM Continuing Professional Development (CME) Certificates will be issued

Abstracts deadline is January 31, 2016. Submissions should include title, authors with location and eaddress, and a text of up to 250 words and two references connected to statements in the text. Abstracts should be preferably structured with objectives, methods, findings, discussion, and conclusions, and reflect either a systematic literature review, a data analysis, a consultation process, or a commentary.

Conference Secretariat: For further information as well as Registration and Abstract Forms, please visit www.personcenteredmedicine.org and write to the ICPCM Secretariat at Int'l Center for Mental Health, Mount Sinai School of Medicine, Fifth Ave \& 100 St, Box 1093, New York NY 10029, USA. E: ICPCMsecretariat@,aol.com. 


\section{PROGRAM OUTLINE}

\section{PRE-CONFERENCE WORKMEETINGS ON PERSON-CENTERED MEDICINE: \\ SUNDAY APRIL 10, 2016}

Venue: Auxilliary Halls one floor under the Marcel Jenny Auditorium, 4 rue Gabrielle-Perret-Gentil CH-1211 Geneva 4, Switzerland.

9:00 - 5:00 PM Pre Conference Institutional Work Meetings

5:00 - 6:00 PM IJPCM Editorial Board Meeting

6:00 - 7:00 PM ICPCM Board Meeting

CORE CONFERENCE FIRST DAY, MONDAY APRIL 11, 2016

Geneva University Hospital Marcel Jenny Auditorium and Auxiliary Halls

8:00 - 8:30 AM Registration and check-in

8:30 - 8:45 AM Conference Opening

Welcoming words from officers of the ICPCM, Geneva University, and World Health

Organization

(Organizational Note for all Sessions: Each of the regular sessions would have 3-5 scholarly presentations (all typically involving systematic literature reviews or data-based studies) made by 1-2 core invitees, 1-2 WHO, WMA or Wonca reps, 0-1 specially supported invitees, and 1-2 non-supported contributors selected from those submitting abstracts on their own.)(Each presentation 8 minutes followed by discussion 7 minutes, and ample general discussion and conclusions at the end)
8:45 - 10:15 AM
Plenary Symposium 1
10:15 - 10:45 AM
Coffee Break and Poster Session
10:45 - 12:15 PM
Plenary Symposium 2
$12: 15-1: 15 \mathrm{PM}$
Lunch (open)
1:15 - 2:45 PM
Parallel Sessions 1: A and B
2:45 - 3:00 PM
Coffee Break
3:00 - 4:30 PM
Parallel Sessions 2: A and B
4:30 - 4:45 PM
Coffee Break
4:45 - 6:30 PM
General Assembly of the International College of Person-centered Medicine
7:00 - 10:00PM
Conference Dinner

CORE CONFERENCE SECOND DAY, TUESDAY APRIL 12, 2016 Geneva University Hospital Marcel Jenny Auditorium and Auxiliary Halls

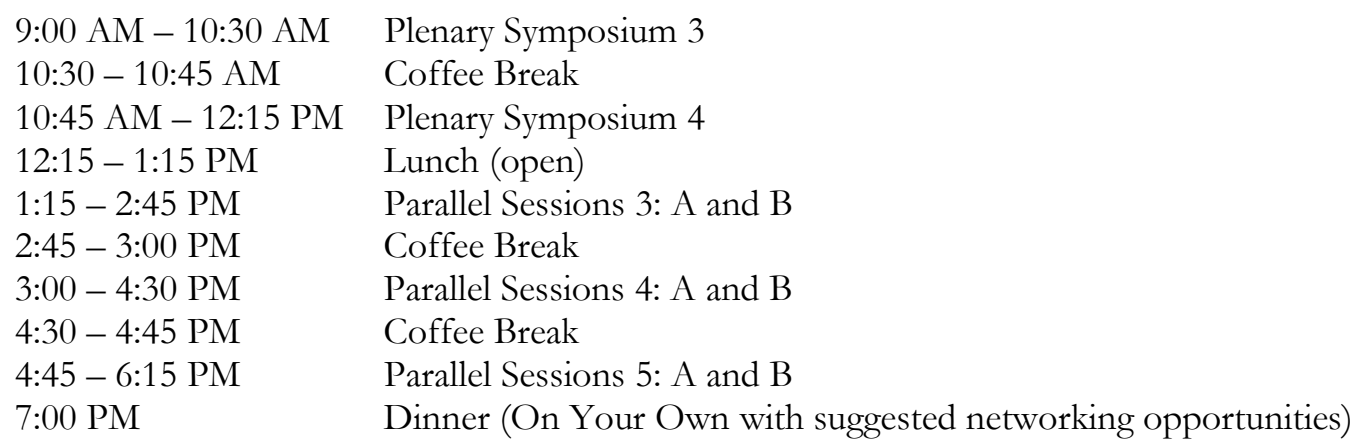

8:30 AM - 9:00 AM

9:00 AM - 10:30 AM

10:30 -10:45 AM

10:45 AM - 11:45 AM

11:45-12:00M
Paul Tournier Award Lecture

Plenary Symposium 5

Coffee Break

Plenary Closing Session

Break 
